\title{
Analysis of large-scale integration of renewable energy sources in the Mexican electricity system
}

\author{
J. J. Vidal-Amaro ${ }^{1}$, P. A. Østergaard ${ }^{2}$ \& C. Sheinbaum-Pardo ${ }^{1}$ \\ ${ }^{1}$ Instituto de Ingeniería, \\ Universidad Nacional Autónoma de México, México \\ ${ }^{2}$ Aalborg University, Denmark
}

\begin{abstract}
The Mexican electricity consumption is highly based on fossil fuels. In 2012 only $15 \%$ of the electricity generation was produced using renewable energy sources (RES) and most of the new installed capacity during the last decade has been based on combined cycle power plants. On the other hand, Mexico is a land of ample opportunities for renewable energy exploitation that could lower its dependency on fossil fuels. Recently, the Mexican Congress approved a regulation limiting fossil fuel-based electricity generation to $65 \%$ by the year 2024 , to $60 \%$ by 2035 and to $50 \%$ by 2050 . In this work we investigate the potential for renewable energy integration into the Mexican electricity system. We construct three scenarios (low, mid and high biomass) for achieving the 2024 target and analyse the electricity system response to varying contributions of wind and solar power production to the scenarios. The minimum complementary capacity based on fossil fuels needed to cover the demand without electricity imports is also assessed. Results indicate that within each scenario several combinations of bio, wind and solar power make a minimum of $35 \%$ RES electricity production possible. However, in every scenario there is only one combination resulting in the minimum overall capacity. Biomass has the highest effectiveness in terms of high RES production with the lowest needed overall power generating capacity.
\end{abstract}

Keywords: energy systems analyses, EnergyPLAN simulation, renewable energies, electricity system, Mexico. 


\section{Introduction}

At the end of 2012, the installed capacity in Mexico came to $51.7 \mathrm{GW}$ of which (34.8\%) $18 \mathrm{GW}$ was Combined Cycle (CC), $17.3 \mathrm{GW}$ (33.5\%) was conventional condensing power plants (PPs) on coal or fuel oil, $2.1 \mathrm{GW}(4.14 \%)$ of singlecycle gas turbines (GT), $252 \mathrm{MW}(0.48 \%)$ on internal combustion engines (ICE), $11.2 \mathrm{GW}(21.73 \%)$ on large scale hydro power, $1.6 \mathrm{GW}(3.1 \%)$ of nuclear power, 812MW (1.56\%) of geothermal plants and $598 \mathrm{MW}(1.15 \%)$ of wind power [1].

In 2008, the Mexican Congress mandated limits in the use of fossil fuels for electricity generation of $65 \%$ by $2024,60 \%$ by 2035 and $50 \%$ by 2050 . The Ministry of Energy (SENER) has included these goals in Mexico's policies for the development of the electricity sector; however, the lack of technical and economic studies on the large-scale integration of RES in Mexico has led to an absence of exact quantitative targets in the scenarios presented by SENER. Moreover, as the limit is only on the fossil fuels' share, nuclear power is considered in two of the three SENER scenarios as a necessary energy source to achieve the 2024 target [2]. The only nuclear power plant in Mexico began operating in 1990, although, the works to build it started in 1970. Since then, nuclear power in Mexico has faced a strong opposition [3].

Mexico is on the other hand a land endowed with important potentials for exploiting RES. The overall bioenergy potential in Mexico is between $33 \mathrm{GW}_{\mathrm{e}}$ and $50 \mathrm{GW}_{\mathrm{e}}$ of continuous electricity production [4-7]. The overall hydropower potential reaches $53 \mathrm{GW}[6,8]$. The mean daily solar irradiation across Mexico is $5.5 \mathrm{kWh} / \mathrm{m}^{2}$; one of the highest solar potentials in the world [9]. Different studies report an additional feasible geothermal power potential from current geothermal capacity of up to $4.6 \mathrm{GW}_{\mathrm{e}}$ plus around up to $7.2 \mathrm{GW}_{\mathrm{e}}$ as probable and possible reserves $[6,7,10]$. Studies conducted for wind power estimate a potential of about $71 \mathrm{GW}$ considering capacity factors (CF) higher that $20 \%$ [6, $8,11]$. For $\mathrm{CF}$ above $30 \%$ the potential is assessed at $11 \mathrm{GW}$ [12] and for $\mathrm{CF}$ higher than $35 \% 5.2 \mathrm{GW}[13,14]$.

One of the characteristics of high-RES energy systems is the fluctuating nature of some of the sources, where wind, solar, and wave power typically is beyond control, while others including run-of-river hydro and geothermal are relatively stable in nature but of a use-it-or-lose-it nature. Dammed hydro and biomass are the main RES that are both dispatchable and storable. The implication of this is that for high-RES scenario analyses for Mexico, a high temporal resolution is required to capture the fluctuations of the various RES in order to ensure that the systems retains proper load-following capabilities. Studies on RES in Mexico and the Mexican electricity system can be found in [15-17], however a literature search does not identify analyses combining RESpotential estimations with simulations of technical feasibility.

The objective of this study is to evaluate the RES possibilities to meet Mexico's electricity-demand growth and fulfill 2024 clean energy targets with RES. For these reasons, in this paper we propose 35\% RES scenarios for 2024 and disregard nuclear power as a viable energy source. The scope of this study is 
thus three-fold: To identify RES potentials in Mexico, to establish high RES scenarios for the Mexican electricity system and to analyze the technical feasibility of the scenarios for achieving the 2024 target.

\section{Methodology}

Two variables are chosen to evaluate the possibilities for RES integration into the Mexican electricity system: RES electricity share and overall installed capacity. To take into account the fluctuations in RES as well as variations in electricity demand, the EnergyPLAN model [18] is utilized to simulate and evaluate the RES integration into the system. EnergyPLAN has been applied to a series of analyses on local and national levels in various countries, i.e. Denmark [19]; it also has been applied to analyze the performance of various technologies in energy systems, i.e. storages [20]; and grid capabilities for integrating RES [21]. Hourly energy demand and RES production values are necessary to evaluate the system over an entire year.

The scenarios evaluation is conducted according to the following steps:

1. Establish a minimum RES-based energy share of the system.

2. Acquire hourly production data for relevant RES and hourly demand profiles for a typical year. Whenever possible, actual data must be utilized.

3. Establish different electricity system scenarios with possible capacity ranges for every RES proposed for the system along with nuclear power or fossil fuels values from current system. RES ranges must be defined in accordance with previous evaluations of RES potentials. Given that stability and loadfollowing capability are the most important characteristics required in a system, dispatchable RES (D-RES) production based on dammed hydro, biomass or geothermal power form the first element in the scenarios and the establishment of specific capacities of these is the first step. The second step is to include in every scenario capacity ranges for any available fluctuating renewable energy sources (FRES), such as wind, PV, etc. The third step is to include values for fossil fuels or nuclear power from the current electricity system. This conventional capacity corresponds solely to projects under construction or power plants with remaining lifetimes past the target date (see Sections 5 and 6). Considering that the installation of additional conventional power originally has been dismissed and due to the fluctuating nature of RES, the scenarios built may not satisfy the demand at all times. This possible power deficit must be covered by additional dispatchable capacity or by imports.

4. Evaluate the scenarios using the EnergyPLAN model. Capacity values defining each scenario have to be input to EnergyPLAN for each scenario simulation. Discrete FRES values have to be chosen to conduct the corresponding calculation of RES share, power deficit and EEP. Simulations are carried out by fixing the value of one FRES (i.e., wind) and making one calculation for every representative value of the remaining FRES (PV, etc.). Thus, for every scenario built in step 3 , it is possible to obtain a clear picture 
of the system's response to the contributions of every RES. Power deficits calculated at this point reveal the magnitude of additional dispatchable capacity (conventional power or D-RES) necessary to successfully integrate RES in each scenario. Conventional power systems are chosen as the alternatives, so every scenario can be identified by the amount of RES power incorporated and by the complementary conventional capacity necessary to keep the system self-sufficient.

5. Identify the combinations of RES and fossil fuels capacities that achieve the minimum RES share target with the minimum overall installed capacity for every scenario evaluated. In this stage, the overall installed capacity must include the value given by the possible power deficits, which has to be covered by adding conventional capacity, as explained in step 4.

It is chosen as the optimal mix scenario the combination resulting in the minimum total installed capacity for the system that accomplish with the RES production target. As a number of different scenarios may accomplish the target with near-optimal total capacities, this domain of scenarios can also be considered as alternatives that may later be analyzed by i.e. an economic point of view.

\section{The Mexican electricity system}

In 2012, the Mexican power sector produced 260.4 TWh of which 221.6 TWh $(85 \%)$ were produced by fossil fuels. Figure 1 shows the hourly electricity demand in Mexico in 2012. During the previous decade 2001-2011 the maximum electricity demand (MED) in Mexico grew at an annual rate of $2.6 \%$, in 2012 the MED reached $39 \mathrm{GW}$ [22]. According to the public utility (CFE), the MED for the year 2024 is expected to reach $60.9 \mathrm{GW}$ and the total annual electricity consumption (TAEC) is expected at 440.9 TWh [22]. These values of TAEC and MED are taken in this study as the target values to attend by 2024 and as the references for building the future high RES scenarios in Section 5.

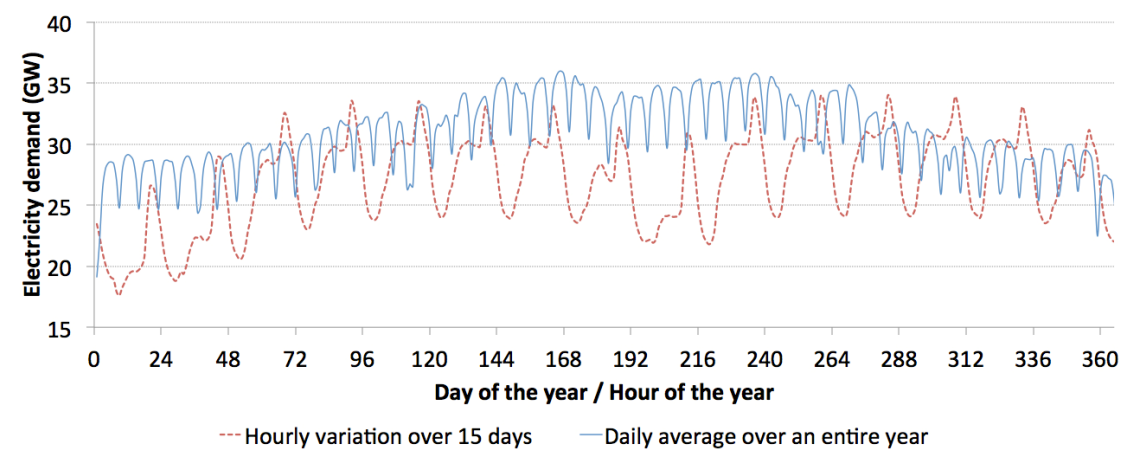

Figure 1: Hourly variation of electricity demand for the first 15 days. Daily average over the year in Mexico (2012) (based on data from CFE). 


\section{Potentials of RES for the future Mexican electricity system}

\subsection{Biomass}

Energy resources from agricultural residues, livestock and municipal waste could account for an overall electric capacity of up to $23 \mathrm{GW}$ - or more depending on operational mode and number of annual operating hours for the different units of which livestock waste could account for up to $14 \mathrm{GW}_{\mathrm{e}}$ [6] in biogas $\mathrm{CC}$ considering an electric efficiency of $48 \%$, agricultural residues to $8.14 \mathrm{GW}_{\mathrm{e}}$ [7] in condensing PPs with electric efficiencies of $28 \%$ and municipal waste to $914 \mathrm{MW}_{\mathrm{e}}$ on biogas $[4,5]$. As forest resources could also be used for non-energy purposes, are not considered as a viable energy source in this study.

\subsection{Hydro and geothermal power}

There is an extra feasible potential of at least $2.2 \mathrm{GW}_{\mathrm{e}}$ [7]. Thus in the high RES scenarios shown in Section 5, geothermal power accounts for $2.2 \mathrm{MW}_{\mathrm{e}}$ or an increase of $1,313 \mathrm{MW}_{\mathrm{e}}$ from the current $887 \mathrm{MW}_{\mathrm{e}}$ of installed capacity.

Current feasibility studies lead to an additional potential of $5 \mathrm{GW}$ of largescale dammed hydroelectric plants [6]. The addition of this capacity to current hydropower would total $16.3 \mathrm{GW}$; thus in the high RES scenarios, this capacity is the target for hydropower by 2024. Figure 2 shows the hydroelectric production curve in Mexico. The total annual hydroelectric generation is determined by the amount of water supplied by the rainfalls during the season, which in a typical year allow the generation of $33 \mathrm{TWh} /$ year. For the high RES scenarios, the $16.3 \mathrm{GW}$ of hydropower capacity would generate up to 55 $\mathrm{TWh} /$ year [22].

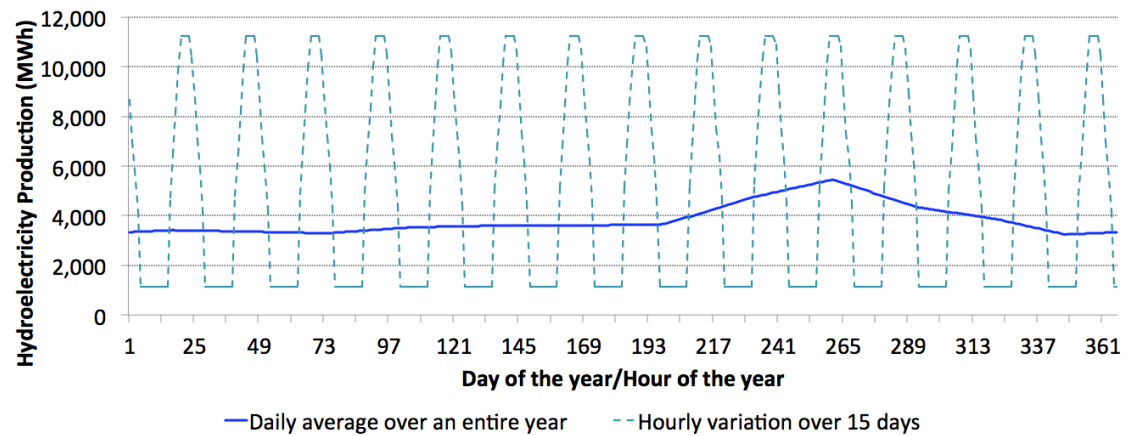

Figure 2: Daily average hydroelectricity production for the entire year and hourly hydroelectric production 15 days in Mexico 2012 (constructed with data from CFE). 


\subsection{Wind power}

Wind power with capacity factors higher than $20 \%$ has a potential of $71 \mathrm{GW}$ [11]. A range of between $1 \mathrm{GW}$ and $70 \mathrm{GW}$ is applied in the high RES scenarios. Wind data distributions have been constructed considering wind profiles from six different locations in order to account for the large local variations given by the size of Mexico. These six correspond to locations with capacity factors higher than $20 \%$. Figure 3 shows the hourly wind variation for all locations equally weighted for a low wind production year.

The hourly distribution curves are constructed based on a modelling of wind farms in these areas using the WindPRO model [23]. WindPRO is able to use 50m height MERRA data (Modern Era-Retrospective Analysis for Research and Applications [24]) from NASA combined with a wind flow model to assess annual as well as hourly wind productions from given wind turbines or wind farms. For these analyses, quadratic wind farms with $5 * 5$ wind turbines in a onekilometre grid are modelled using $3 \mathrm{MW}$ Vestas v90 turbines. A sheer factor of 0.2 is applied to adjust to the actual $90 \mathrm{~m}$ hub-height of this wind turbine. Simulations operate with one-year time frame, data from years 2004, 2005 and 2011 are used to evaluate future scenarios in years of average, low and high wind production.

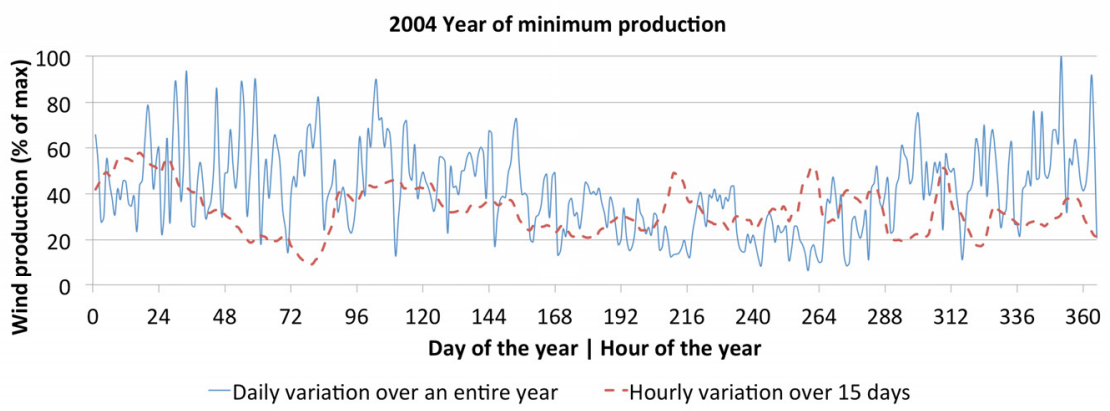

Figure 3: Hourly and daily wind variation for Baja California, Nuevo Leon, Tamaulipas, Oaxaca, Zacatecas and Ciudad Juarez Chihuahua, Mexico. Normalized values where $100 \%$ is the peak hourly/daily production.

\subsection{Solar PV power}

We analyse the impact of between $1 \mathrm{GW}$ and $40 \mathrm{GW}$ of PV capacity for the future high RES scenarios. Hourly data for PV (Fig. 4) were calculated for two locations in northeast Mexico. The first location in the Sonora Desert receives the highest Daily Global Irradiation (DGI) levels along the year, ranging from $14 \mathrm{MJ} / \mathrm{m}^{2}$ day in winter to $30 \mathrm{MJ} / \mathrm{m}^{2}$ day in summer, while the second location in the state of Zacatecas receives DGI levels from $14 \mathrm{MJ} / \mathrm{m}^{2}$ day to $27 \mathrm{MJ} / \mathrm{m}^{2}$ day [9]. 




Figure 4: Hourly global irradiation values on tilted surface for Sonora and Zacatecas Mexico for five days in October. Tilt angle equals the latitude on each location.

Hourly data for PV where obtained using a self-written "C" computer program for evaluating the equations of the Collares-Pereira and Rabl model and the anisotropic sky model [25], for calculating Hourly Global Irradiation on tilted surfaces $\left(\mathrm{HGI}_{t}\right)$ from monthly averaged DGI data [9]. The HGI $\mathrm{H}_{t}$ curve has the typical symmetric insolation shape with the maximum occurring at noon for each day as shown on Fig. 4 which presents data detailed for a week in October for the two selected locations as well as for the combination of them; the averaged curve is the one utilized in the analysis as that one reflects the combined hourly production values from both locations weighted evenly.

\section{The high-RES scenarios}

For the high RES scenarios it is considered that some of the present capacity will be retired according to the current CFE's retirement plan. The installed capacity by energy source and technology will be as shown in Table 1. Three different high RES scenarios have been built using low, mid and high capacities for biomass and biogas: HighRES-LowBio, HighRES-MidBio and HighRESHighBio respectively. All three keep the same capacity on geothermal, hydro, fossil fuels and nuclear, the first two were increased with regard their current values. The impact of PV and wind power is analysed and thus are listed as ranges in Table 1.

Table 1: Installed capacity by fuel and technology in the high RES scenarios.

\begin{tabular}{|c|c|c|c|c|c|}
\hline TECHNOLOGY & FUEL & $\begin{array}{c}\text { Capacity } 2012 \\
\text { MW }\end{array}$ & $\begin{array}{c}\text { HighRES-LowBio } \\
\text { MW }\end{array}$ & $\begin{array}{c}\text { HighRES-MidBio } \\
\text { MW }\end{array}$ & $\begin{array}{c}\text { HighRES-HighBio } \\
\text { MW }\end{array}$ \\
\hline \multirow{2}{*}{ Combined Cycle } & Biogas & - & 1000 & 2500 & 5000 \\
\hline & Natural Gas & 18029 & $>21494$ & $>21494$ & $>21494$ \\
\hline \multirow[t]{2}{*}{ Nuclear } & & 1610 & 1610 & 1610 & 1610 \\
\hline & Fuel Oil & 11951 & 3880 & 3880 & 3880 \\
\hline \multirow{3}{*}{ Condensing PP } & Coal & 2600 & 2600 & 2600 & 2600 \\
\hline & Coal/Fuel Oil & 2778 & 2778 & 2778 & 2778 \\
\hline & Biomass & - & 2000 & 4000 & 6000 \\
\hline Geothermal & & 812 & 2400 & 2400 & 2400 \\
\hline Gas Turbine & Natural Gas & 2146 & 693 & 693 & 693 \\
\hline Hydroelectric & & 11256 & 16532 & 16532 & 16532 \\
\hline Wind power & & 598 & 1,000 to 70,000 & 1,000 to 70,000 & 1,000 to 70,000 \\
\hline PV & & - & 1,000 to 40,000 & 1,000 to 40,000 & 1,000 to 40,000 \\
\hline TOTAL & & 51780 & 56,986 to 164,987 & 60,487 to 168,487 & 64,987 to 172,987 \\
\hline
\end{tabular}


As explained in Section 2, additional complementary conventional capacity may be necessary; hence, NG-CC has been chosen as the technology to cover possible power deficits. The capacities of NG-CC PPs listed in Table 1 represent only current CFE projects until 2024. The overall minimum NG-CC capacity to make the system self-sufficient (including that corresponding to power deficits) for each scenario are thus presented in Section 6 (Results).

\section{Results}

\subsection{Annual RES electricity production share}

Figure 5 shows the annual RES electricity shares for the HighRES-LowBio scenario using the 2004 wind production profile to evaluate the electricity system in low wind production years. Every curve in Fig. 5 corresponds to a fixed wind capacity when PV increases. Mexico's 2024 target can be achieved with different combinations of wind and PV power. For every defined wind capacity, a specific minimum value of PV power that makes the $35 \%$ RES production share possible is corresponded. The higher the wind power value, the lower the corresponding PV. Thus, there is a wind capacity beyond which PV is no longer necessary; wind capacities higher than this limit produce RES shares over $35 \%$ regardless PV is included or not. Also Fig. 5 shows that more than $85 \%$ of the electricity could be produced if the highest analyzed wind-PV capacities were installed.

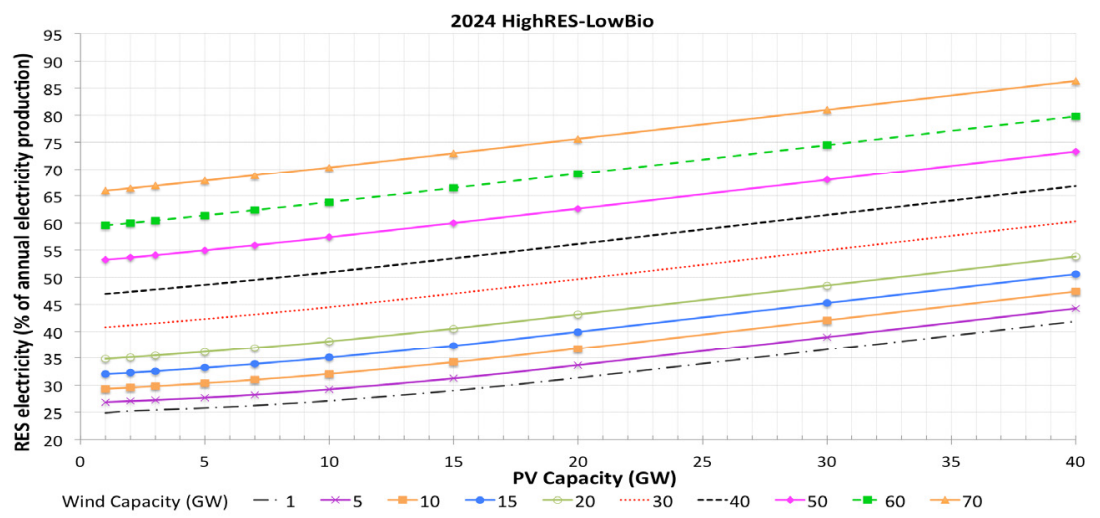

Figure 5: HighRES-LowBio scenario: share of RES electricity production. Analysis uses 2004 wind data, year of low wind production.

The RES share values for the HighRES-MidBio and HighRES-HighBio scenarios are $20 \%$ and $40 \%$ respectively higher than the HighRES-LowBio's values shown in Fig. 5, hence their corresponding graphs keep the same shape but moved upwards by those factors. These graphs are not presented to save space. Higher bioenergy power creates higher RES electricity shares for equal wind-PV capacities. Therefore, the highest RES electricity shares are produced in the HighRES-HighBio scenario and a 35\% RES share can be generated even 
without wind or PV contributions. On the other hand, the wind limits beyond which PV are no longer necessary in the HighRES-LowBio and HighRESMidBio scenarios are $20 \mathrm{GW}$ and $15 \mathrm{GW}$, respectively; below these capacities, up to $27 \mathrm{GW}$ of PV power is necessary depending on the wind power selected.

\subsection{Minimum necessary capacity on Natural Gas Combined Cycles}

The minimum overall NG-CC capacity needed to keep the electric system selfsufficient depends on the specific PV and wind capacities along with the bio power defined in every high RES scenario. In the simulations, no contributions from NG-CC were included; thus, the minimum overall NG-CC capacity corresponds to the highest difference occurring at any hour during the year between the electricity demand and the production of all of the energy sources listed in Table 1, with the exception of NG-CC. The NG-CC capacity present a backup cost, which should be minimized. Figure 6 shows the curves of the minimum necessary NG-CC capacities for the high RES-LowBio scenario; each curve corresponds to a fixed wind capacity when PV power increases. From these values, 21.5 GW corresponds to current projects (see Section 5). Minimum $\mathrm{NC}-\mathrm{CC}$ values for the HighRES-MidBio and HighRES-HighBio scenarios are $8 \%$ and $18 \%$ respectively lower than the HighRES-LowBio's values shown in Figure 6, hence their corresponding graphs keep the same shape but moved downwards by those factors. These graphs are not presented to save space.

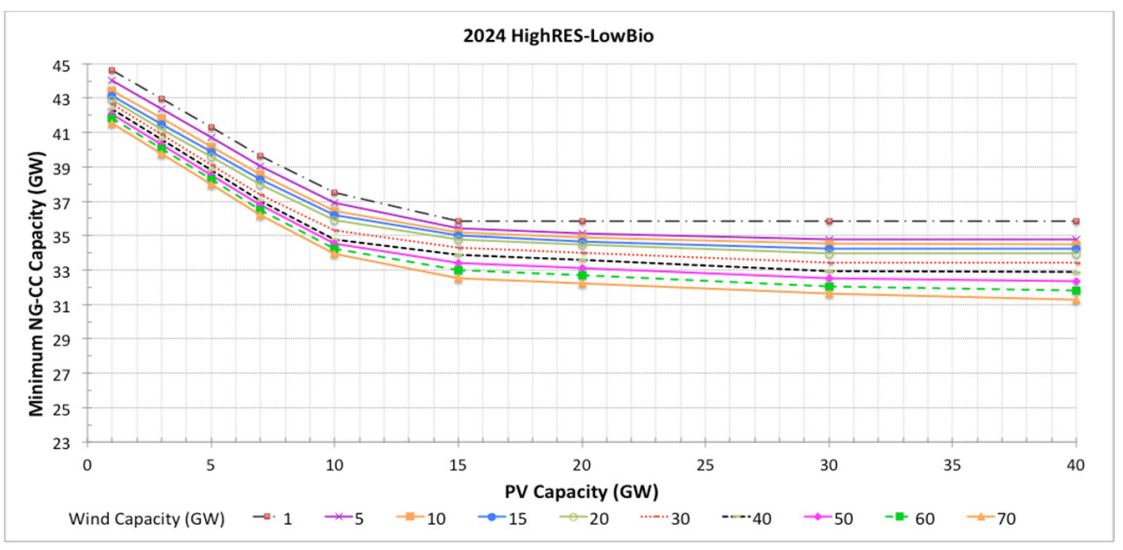

Figure 6: HighRES-LowBio scenario. Minimum necessary NG-CC capacity. Analyses using 2004 wind data, year of minimum wind production.

Three aspects can be highlighted from the graphs in Fig. 6:

1. Increasing amounts of bioenergy power proportionally reduce the dependence of NG-CC.

2. PV power highly contributes to drastic reductions in NG-CC needs, ranging from 1 to $15 \mathrm{GW}$. Beyond this PV capacity, the curves have smaller slopes and PV does not contribute to greater reductions in NG-CC needs.

3. The highest reductions are achieved with combinations of wind and PV values within the 1 to $15 \mathrm{GW}$ PV power gap. Thus, increasing only wind 
power does not reduce NG-CC needs to the same magnitude as those achieved with, i.e., a fixed wind capacity and increasing PV power. Hence, PV power plays an important role for reducing back up (NG-CC) needs.

\subsection{Optimal bio, wind and PV combination}

The 2024 target can be achieved with any combination of Bio, Wind and PV (BWPV) power that guarantee 35\% RES electricity production throughout the year. This objective is reachable in any of the three high RES scenarios and with different shares of wind and PV power. PV power is required for wind capacities lower than $20 \mathrm{GW}$ in the HighRES-LowBio and HighRES-MidBio scenarios; on the other hand, the 2024 target is reached with the HighRES-HighBio scenario even without contributions from wind or PV power. However, as shown in Fig. 6 , any combination from BWPV is also related to a minimum NG-CC capacity. As explained in Section 2, we choose as the optimal mix the combination that reaches the RES share target, resulting in the minimum total capacity.

Table 2 shows the BWPV and NG-CC combinations for the three high RES scenarios that make the 2024 target possible with a minimum total capacity; in addition, these combinations form the domain of near-optimal scenarios. For the HighRES-LowBio scenario, the combinations resulting in the lowest capacity corresponds to $15 \mathrm{GW}$ of wind power. The HighRES-MidBio total capacity values are lower than the HighRES-LowBio values, and the lowest corresponds to $5 \mathrm{GW}$ of wind power. As the HighRES-HighBio scenario makes the 2024 target feasible even with the lowest evaluated wind-PV capacities, the combination with the minimum overall capacity or optimal mix is that with 1 GW wind power and $1 \mathrm{GW}$ on PV; other combinations result in higher totals. Note that higher bio capacities allow drastic reductions in total power; these reductions are on the order of two times the bio capacity additions when comparing the results for equal wind inputs.

Table 2: Combinations resulting in the lowest total capacities from BWPV and NG-CC and total capacity including remaining power on Nuclear, Geothermal, Hydro and non NG-CC power plants.

\begin{tabular}{|c|c|c|c|c|c|c|c|}
\hline Scenario & Bio $(M W)$ & Wind (MW) & PV (MW) & NG-CC (MW) & Subtotal (MW) & $\begin{array}{c}\text { Remaining } \\
\text { power (MW) }\end{array}$ & Total (MW) \\
\hline & & 1,000 & 27,000 & 35,800 & 66,800 & & 97,293 \\
\hline & & 5,000 & 22,000 & 35,000 & 65,000 & & 95,493 \\
\hline \multirow[t]{5}{*}{ HighRES-LowBio } & 3,000 & 10,000 & 16,000 & 35,213 & 64,213 & 30,493 & 94,706 \\
\hline & & 15,000 & 10,000 & 36,185 & 64,185 & & 94,678 \\
\hline & & 20,000 & 1,000 & 43,000 & 67,000 & & 97,493 \\
\hline & & 1,000 & 20,000 & 32,324 & 59,824 & & 90,317 \\
\hline & & 5,000 & 15,000 & 31,935 & 58,435 & & 88,928 \\
\hline \multirow[t]{3}{*}{ HighRES-MidBio } & 6,500 & 10,000 & 7,000 & 35,300 & 58,800 & 30,493 & 89,293 \\
\hline & & 15,000 & 1,000 & 39,628 & 62,128 & & 92,621 \\
\hline & & 20,000 & 1,000 & 39,408 & 66,908 & & 97,401 \\
\hline HighRES-HighBio & 11,000 & 1,000 & 1,000 & 36,623 & 49,623 & 30,493 & 80,116 \\
\hline
\end{tabular}

In general, energy systems should move towards smart energy systems where sectors are integrated, and particularly for electricity systems, flexibility is 
utilized to help integrate renewable energy [28]. A typical minimum requirement of grid stability providing units is $30 \%$ of the production in a given hour [27]. Conventional PPs and large-scale hydro PPs typically do so. In this analysis, the $30 \%$ minimum share is upheld for all the scenarios. Some studies conclude that $20-25 \%$ of FRES can be integrated without affecting the reliable operation of the electricity grid [28]. Thus for the Mexican electricity system, combinations from the MidBio and HighBio scenarios would require less grid adaptations than combinations from LowBio scenario. However, for a more rigorous analysis of power quality and grid operation, complementing studies have to be conducted using tools adapted for electro-technical analyses rather than for scenario-design and simulation.

\section{Conclusions}

Three high-RES scenarios for Mexico's electricity system to achieve the target of $35 \%$ RES electricity share set for the year 2024 have been established and evaluated utilizing high-temporal resolution data for RES production and electricity demand. Biogas and biomass power were added with three different levels, creating the HighRES-LowBio, HighRES-MidBio and HighRES-HighBio scenarios. Increasing amounts of wind and PV power were analyzed to identify combinations of bio, wind and PV power resulting in a minimum of 35\% RES electricity production. The minimum NG-CC power required for every combination of wind and PV in the three scenarios to make the system selfsufficient was also calculated.

In each high-RES scenario, several wind and PV combinations achieve the minimum $35 \%$ RES target. Every possible configuration is related to a minimum necessary NG-CC capacity, thus only a few combinations achieve the best results in terms of the lowest scenario's total capacity forming the domain of near-optimal mix. The HighRES-HighBio scenario gives the optimal mix with the lowest total capacity equal to $80 \mathrm{GW}$, including $1 \mathrm{GW}$ from wind and PV power respectively.

The near-optimal combinations corresponding to the HighRES-MidBio scenario have lower total capacities than those for the HighRES-LowBio scenario, confirming the important impact that bioenergy has on the scenarios. For the HighRES-LowBio scenario, the combination of $15 \mathrm{GW}$ from wind and $10 \mathrm{GW}$ from PV is the best option, resulting in a total capacity of $95.6 \mathrm{GW}$. For the HighRES-MidBio scenario, the best alternative is with $5 \mathrm{GW}$ from wind and $15 \mathrm{GW}$ from PV power for a total of $88.9 \mathrm{GW}$. Although wind power shows better results than PV power regarding RES electricity-production shares, PV greatly contributes in reducing NG-CC needs; however, there is a $15 \mathrm{GW}$ limit from PV for achieving high reductions in NG-CC. Beyond this capacity, additional PV power only slightly reduces the NG-CC dependence. 


\section{Acknowledgements}

The work presented is the result of a collaboration agreement between the National Autonomous University of Mexico and Aalborg University, Denmark. The work was supported financially by CONACyT and the Engineering Institute of the National Autonomous University of Mexico enabling the lead author a research stay in Denmark.

\section{References}

[1] CFE, Comisión Federal de Electricidad. Informe Anual 2012.

[2] SENER, Secretaría de Energía. Prospective of the Electricity Sector 20122026 (Prospectiva del Sector Eléctrico 2012-2026). Mexico City: 2012.

[3] Redclift M. Mexico's nuclear paradox. Energy Policy 1989; 17: 6-10.

[4] Arvizu F. JL, Jorge M., Huacuz V. Biogás de rellenos sanitarios para la producción de electricidad. Boletín IIE 2003; 28: 118-123.

[5] Masera O, Coralli F, García Bustamante C, Riegelhaupt E, Arias Chalico $\mathrm{T}$, Vega Gregg J, et al. La Bioenergía en México. Situación actual y Perspectivas. Agosto 2011. Mexico: Red Mexicana de Bioenergía; 2011.

[6] SENER, Secretaría de Energía. Renewable Energies Prospective 2012-2026 (Prospectiva de Energías Renovables 2012-2026). Mexico City: 2012.

[7] Una visión al 2030 de la utilización de las energías renovables en México. Mexico City: UAM - Universidad Autónoma Metropolitana; 2005.

[8] SENER, Secretaría de Energía. Energías Renovables para el Desarrollo Sustentable en México. Mexico City: 2006.

[9] Estrada-Cajigal Ramírez V, Almanza Salgado R. Irradiaciones global, directa y difusa en superficies horizontal e inclinada, así como irradiación directa normal, en la República Mexicana. UNAM - Universidad Nacional Autónoma de México, Instituto de Ingeniería; 2005.

[10] Pablo M del P, David NG, Holland FA. Developments in Geothermal Energy in Mexico - Part one: general considerations. Heat Recovery Systems 1985; 5: 277-283.

[11] Hernández-Escobedo Q, Manzano-Agugliaro F, Zapata-Sierra A. The wind power of Mexico. Renewable and Sustainable Energy Reviews 2010; 14: $2830-2840$.

[12] Jaramillo OA, Saldana R, Miranda U. Wind power potential of Baja California Sur, México. Renewable Energy 2004; 29: 2087-2100.

[13] Cancino-Solórzano Y, Gutiérrez-Trashorras AJ, Xiberta-Bernat J. Current state of wind energy in Mexico, achievements and perspectives. Renewable and Sustainable Energy Reviews 2011; 15: 3552-3557.

[14] Elliott D, Schwartz M, Scott G, Haymes S, Heimiller D, George R. Wind Energy Resource Atlas of Oaxaca. National Renewable Energy Laboratory (NREL), Golden, CO.; 2003. 
[15] Islas J, Manzini F, Martínez M. $\mathrm{CO}_{2}$ mitigation costs for new renewable energy capacity in the Mexican electricity sector using renewable energies. Solar Energy 2004; 76: 499-507.

[16] Johnson TM, Alatorre C, Romo Z, Liu F. Low-Carbon Development for Mexico. The World Bank; 2010.

[17] Oropeza-Perez I, Østergaard PA. The influence of an estimated energy saving due to natural ventilation on the Mexican energy system. Energy 2014; 64: 1080-1091. doi: http://dx.doi.org/10.1016/j.energy.2013.11.009.

[18] Lund H. EnergyPLAN | Advanced energy systems analysis computer model n.d. http://www.energyplan.eu/ (accessed October 29, 2014).

[19] Lund H, Mathiesen BV. Energy system analysis of 100\% renewable energy systems - The case of Denmark in years 2030 and 2050. Energy 2009; 34: 524-531. doi: 10.1016/j.energy.2008.04.003.

[20] Connolly D, Lund H, Finn P, Mathiesen BV, Leahy M. Practical operation strategies for pumped hydroelectric energy storage (PHES) utilising electricity price arbitrage. Energy Policy 2011; 39: 4189-4196. doi: 10.1016/j.enpol.2011.04.032.

[21] Alberg Østergaard P. Transmission-grid requirements with scattered and fluctuating renewable electricity-sources. Applied Energy 2003; 76: 247255. doi: 10.1016/S0306-2619(03)00065-5.

[22] CFE, Comisión Federal de Electricidad. POISE, Programa de Obras e Inversiones del Sector Eléctrico 2012-2026.

[23] EMD. WindPro Model n.d. http://emd.dk/WindPRO/ (accessed May 16, 2014).

[24] GMAO MERRA: Modern Era Retrospective-Analysis for Research and Applications n.d. http:/gmao.gsfc.nasa.gov/merra/ (accessed May 16, 2014).

[25] Reindl DT, Beckman WA, Duffie JA. Evaluation of Hourly tilted Surface Radiation Models. Solar Energy 1990; 45: 9.

[26] Lund H, Hvelplund F, Østergaard PA, Möller B, Mathiesen BV, Karnøe P, et al. System and market integration of wind power in Denmark. Energy Strategy Reviews 2013; 1: 143-156. doi: 10.1016/j.esr.2012.12.003.

[27] Østergaard PA. Ancillary services and the integration of substantial quantities of wind power. Applied Energy 2006; 83: 451-463. doi: 10.1016/j.apenergy.2005.04.007.

[28] Mathiesen BV, Lund H, Connolly D, Wenzel H, Østergaard PA, Möller B, et al. Smart Energy Systems for coherent 100\% renewable energy and transport solutions. Applied Energy 2015; 145: 139-154. doi: 10.1016/ j.apenergy.2015.01.075. 